\title{
Long-chain 3-Hydroxyacyl-CoA Dehydrogenase Deficiency
}

\author{
H. Przyrembel ${ }^{1 *}$, C. JAKobs ${ }^{2}$, L. IJlst $^{3}$, J. B. C. De Klerk ${ }^{1}$ and \\ R. J. A. WANDERS ${ }^{3}$ \\ ${ }^{1}$ Department of Pediatrics, Erasmus University Rotterdam, Sophia Children's \\ Hospital, Gordelweg 160, NL-3038 GE Rotterdam, The Netherlands; ${ }^{2}$ Department of \\ Pediatrics, Free University Hospital, De Boelelaan 1117, NL-1081 HV Amsterdam, \\ The Netherlands; ${ }^{3}$ Department of Pediatrics, University Hospital Amsterdam, \\ Meibergdreef 9, NL-1105 Amsterdam, The Netherlands
}

Summary: A new case of 3-hydroxyacyl-CoA dehydrogenase deficiency is described with a relatively benign course.

3-Hydroxyacyl-CoA dehydrogenase (HAD) deficiency (EC 1.1.1.35) as a cause of 3hydroxydicarboxylicaciduria has been suspected in approximately 30 cases (Riudor et al., 1986; Kelley and Morton, 1988; Poll-The et al., 1988; Hale and Thorpe, 1989; Wanders et al., 1989; Dionisi Vici et al., 1990; Hagenfeldt et al., 1990; Hale et al., 1990; Pollitt, 1990). A reduction in activity of the long-chain HAD in fibroblast homogenates has been proved in 6 cases (Wanders et al., 1989; Dionisi Vici et al., 1990; Hale et al., 1990; Rocchiccioli et al., 1990). In one patient a reduction in the activity of short-chain HAD has been found (Hale and Thorpe, 1989). We report on a seventh patient with a proven defect of long-chain HAD, who is now 10 years old and shows, in contrast to most other suspected or proven cases, a relatively benign clinical course.

\section{CASE REPORT}

The patient was born in 1980 as the second child of apparently healthy unrelated parents. Her brother is healthy. Her mother admits to mild symptoms suggestive of hypoglycaemia, but this has never been severe enough to request medical investigation.

The patient was born after a normal pregnancy of 40 weeks with a weight of $3250 \mathrm{~g}$ and a length of $47 \mathrm{~cm}$. At the age of 6 months developmental arrest was noted following a period of increasing feeding problems with vomiting, sweating and hypotonia.

On admittance to the hospital at the age of 6.5 months she was a passive hypotonic

${ }^{*}$ Correspondence: Dr H. Przyrembel, Federal Health Office, Max von Pettenkofer-Institute, Postfach 3300 13, W-1000 Berlin 33, Germany

MS received 22.1.91 Accepted 25.3.91 
child who could not hold up her head, could not turn around and cried weakly. Her weight was below the 3rd centile, her length between the 25 th and 50th centile and her head circumference on the 10th centile. Reflexes were normal as were an EMG and EEG. An ECG was normal, an echocardiogram showed, except for a small atrial septal defect, no abnormalities. Radiography of the head, spine and hand was normal. Blood glucose after a $13 \mathrm{~h}$ fast was $2.0 \mathrm{mmol} / \mathrm{L}$, blood $\mathrm{pH}$ was 7.38 , base excess $-5.0 \mathrm{mmol} / \mathrm{L}$, standard bicarbonate $20 \mathrm{mmol} / \mathrm{L}$. Blood creatinine, lactate, pyruvate, 3-hydroxybutyrate, acetoacetate, thyroid hormones, and cerebrospinal fluid were normal. Free carnitine in plasma was $18.5 \mu \mathrm{mol} / \mathrm{L}$ (normal $>25$ ).

The clinical and chemical findings in connection with the urinary organic acid profile (see results) suggested very strongly that the cause of her disease was a defect in the $\beta$-oxidation of fatty acids but was not medium-chain acyl-CoA dehydrogenase deficiency. Therefore, she was given a diet rich in carbohydrates (75\% of the calories) and poor in fat $(7 \%)$, which resulted in a rapid recovery, weight gain, and normalization of muscle tone and of psychomotor development. She did very well on a highcalorie/high-carbohydrate intake spread over the day with a nocturnal meal at midnight, $0.00 \mathrm{~h}$.

Uncooked starch was tried with a satisfactory result but was not tolerated for any length of time. As she was becoming rather obese owing to the diet she was started on gradual reduction of the carbohydrate intake, and L-carnitine $330 \mathrm{mg}$ twice per day was added, because of consistently low plasma carnitine levels. During an observation period of 9 years there have been three episodes of hypoglycaemia necessitating hospital admittance, twice in association with gastroenteritis and once after physical exhaustion during a skiing vacation.

At the age of 10 years her length is on the 75 th centile, her weight on the 50th centile, and her head circumference on the 60th centile. She is a beautiful sportive girl of normal intelligence. She still takes a nocturnal meal and uses a normocaloric, mildly fat-restricted and carbohydrate-enriched diet plus extra carnitine. There are signs of mild exercise intolerance. There are no indications of cardiac involvement by electrocardiography and echocardiography.

However, recently she showed signs of visual deterioration, namely decreased night vision, photophobia and constriction of the visual field. On fundoscopy the optic discs are somewhat pale with narrow vessels. There are diffuse pigmentary disturbances at the posterior pole and some pigmentations in the periphery. The electrooculogram shows normal potentials at rest and abnormally low responses to light. The electroretinogram gives diminished amplitudes $(30-40 \%)$ for both rods and cones.

\section{METHODS}

Organic acids in the urine were determined and identified by capillary GC-MS (Jakobs et al., 1981).

Leukocytes (and platelets) were isolated from blood samples from the patient and from control subjects with EDTA as an anticoagulant (Wanders et al., 1986a).

Oxidation of octanoate and palmitate was measured in isolated leukocytes by measuring the release of ${ }^{14} \mathrm{CO}_{2}$ and ${ }^{14} \mathrm{C}$-radiolabelled water-soluble products from 
$\left[1-{ }^{14} \mathrm{C}\right]$ octanoate and $\left[1-{ }^{14} \mathrm{C}\right]$ palmitate, respectively. Leukocytes were incubated for $60 \mathrm{~min}$ at $37^{\circ} \mathrm{C}$ in a medium containing phosphate-buffered saline plus $200 \mu \mathrm{mol}$ [1$\left.{ }^{14} \mathrm{C}\right]$ octanoate or $\left[1-{ }^{14} \mathrm{C}\right]$ palmitate. Termination of the reaction and quantification of ${ }^{14} \mathrm{CO}_{2}$ and ${ }^{14} \mathrm{C}$-radiolabelled water-soluble products was as described previously (Wanders et al., 1986b).

The activity of HAD in fibroblast homogenate was measured as described elsewhere (Wanders et al., 1990) in a medium containing $50 \mathrm{mmol} 2$-( $N$-morpholino)ethanesulphonic acid (MES), $100 \mathrm{mmol}$ potassium phosphate, $0.1 \mathrm{mmol}$ dithiothreitol, $0.1 \%$ (w/v) Triton X-100, $100 \mu$ mol NADH (final pH 6.16). Reactions were started by adding the 3-oxoacyl-CoA ester at a final concentration of $25 \mu \mathrm{mol} / \mathrm{L}$.

\section{RESULTS}

The urinary organic acid concentrations were raised and the profile (Table 1) was characteristic with $\mathrm{C}_{6}-\mathrm{C}_{12}$ saturated and unsaturated $(\Delta)$ dicarboxylic acids and with 3-hydroxy saturated and unsaturated dicarboxylic acids with 6 to 14 carbon atoms. The ratio of 3-hydroxyadipic over adipic acid was 2.25 and the ratio of total 3hydroxydicarboxylic over dicarboxylic acids was 2.07 . There were negligible amounts of 3-hydroxybutyrate and some 5-hydroxyhexanoate. Glycine conjugates were not present.

The results of the oxidation of octanoate and palmitate in leukocytes are given in Table 2: there is a normal oxidation of octanoate and a decrease in palmitate oxidation giving rise to an abnormally low ratio of $\mathrm{C}_{16} / \mathrm{C}_{8}$ oxidation.

The activity of HAD in homogenates of cultured fibroblasts was measured with three different substrates (Table 3). There is normal activity with acetoacetyl-CoA and a decreased activity especially with 3-ketopalmitoyl-CoA. This means that there is normal activity of the short-chain HAD and a decrease of the long-chain HAD

Table 1 Organic acids in a urine sample when the patient was 7 months old $[\mu \mathrm{mol} / \mathrm{mmol}$ creatinine]

\begin{tabular}{|c|c|c|c|}
\hline $\begin{array}{l}\text { Lactic } \\
\text { Pyruvic } \\
\text { 3-Hydroxybutyric } \\
\text { 5-Hydroxyhexanoic }\end{array}$ & $\begin{array}{l}39 \\
29 \\
11 \\
36\end{array}$ & $\begin{array}{l}\text { Adipic } \\
\text { 3-Hydroxyadipic } \\
\Delta_{2} \text {-Adipic } \\
\Delta_{3} \text {-Adipic }\end{array}$ & $\begin{array}{r}474 \\
1066 \\
37 \\
7\end{array}$ \\
\hline $\begin{array}{l}\text { Suberic } \\
\text { 3-Hydroxysuberic } \\
\Delta_{4} \text {-Suberic } \\
\text { 3-Hydroxy- } \Delta \text {-suberic }\end{array}$ & $\begin{array}{r}120 \\
26 \\
43 \\
44\end{array}$ & $\begin{array}{l}\text { Sebacic } \\
\text { 3-Hydroxysebacic } \\
\Delta_{3} \text {-Sebacic } \\
\Delta_{4} \text {-Sebacic } \\
\text { 3-Hydroxy- } \Delta \text {-Sebacic }\end{array}$ & $\begin{array}{r}97 \\
228 \\
42 \\
56 \\
72\end{array}$ \\
\hline $\begin{array}{l}\text { 3-Hydroxy-C } \mathrm{C}_{12} \text {-dioic } \\
\text { 3-Hydroxy- } \Delta-\mathrm{C}_{12} \text {-dioic } \\
\text { 3-Hydroxy } \Delta, \Delta-\mathrm{C}_{12} \text {-dioic }\end{array}$ & $\begin{array}{r}89 \\
58 \\
4\end{array}$ & $\begin{array}{l}\text { 3-Hydroxy- } \mathrm{C}_{14} \text {-dioic } \\
\text { 3-Hydroxy- } \Delta-\mathrm{C}_{14} \text {-dioic }\end{array}$ & $\begin{array}{l}19 \\
35\end{array}$ \\
\hline \multicolumn{2}{|c|}{$\begin{array}{l}\text { Ratio, 3-hydroxy-adipic/adipic } \\
\text { Ratio, 3-hydroxydicarboxylic/dicarboxylic }\end{array}$} & $\begin{array}{l}2.25 \\
2.07\end{array}$ & \\
\hline
\end{tabular}


Table $2 \beta$-Oxidation activity $\left[\mu \mathrm{molh}^{-1}(\mathrm{mg} \text { protein })^{-1}\right]$ in leukocytes of the patient and of controls

\begin{tabular}{lccc}
\hline & Octanoate & Palmitate & $C_{16} / C_{8}$ ratio \\
\hline Controls $^{\mathrm{a}}$ & $3.64-3.96(4)$ & $2.58-2.84(4)$ & $0.71-0.74$ \\
Patient & $3.55 / 3.83$ & $1.58 / 1.72$ & 0.45 \\
\hline
\end{tabular}

${ }^{a}$ Numbers of individuals tested in parentheses

Table 3 3-Hydroxyacyl-CoA dehydrogenase activity with three different substrates in cultured skin fibroblasts of the patient $\left[\mathrm{nmol} \mathrm{min}^{-1}(\mathrm{mg} \text { protein })^{-1}\right]$

\begin{tabular}{lcc}
\hline & Patient & $\begin{array}{c}\text { Controls* } \\
\text { (mean } \pm \text { SD) }\end{array}$ \\
\hline Acetoacetyl-CoA & 113.6 & $117 \pm 18.1(13)$ \\
3-Ketooctanoyl-CoA & 28.7 & $59.1 \pm 9.2(13)$ \\
3-Ketohexadecanoyl-CoA & 21.9 & $83.9 \pm 11.9(13)$ \\
$\quad$ (3-Ketopalmitoyl-CoA) & & \\
$\mathrm{C}_{8} / \mathrm{C}_{4}$ activity ratio & 0.25 & $0.53 \pm 0.07(13)$ \\
$\mathrm{C}_{16} / \mathrm{C}_{4}$ activity ratio & 0.19 & $0.75 \pm 0.09(13)$ \\
\hline
\end{tabular}

* Numbers of individuals tested in parentheses

activity ( $25 \%$ of the normal mean), which is also apparent in a $75 \%$ reduction in the ratio of the activities with ketopalmitoyl-CoA over acetoacetyl-CoA.

\section{DISCUSSION}

An increase in the urinary excretion of 3-hydroxydicarboxylic acids can occur as a consequence of a defective HAD but can also be a feature of other inherited or acquired diseases, e.g. Reye syndrome, ketoacidosis, severe progressive hepatic cirrhosis, medium-chain acyl-CoA dehydrogenase deficiency, generalized peroxisomal dysfunction (for differential diagnosis see Pollitt, 1990) and possibly a long-chain ketoacyl-CoA thiolase deficiency (Ribes et al., 1989). Most of these conditions show, in addition, other typical metabolites and clinical features, and the ratio of hydroxydicarboxylic acids to dicarboxylic acids will be less than unity.

The lack of enzymatic confirmation of the presumptive diagnosis of long-chain HAD deficiency in many of the cases discussed below at present leaves uncertainties about the obligatory nature of some of the reported symptoms.

3-Hydroxydicarboxylic aciduria due to long-chain HAD deficiency is very similar in its acute symptoms to other defects of mitochondrial $\beta$-oxidation of fatty acids like long- and medium-chain acyl-CoA dehydrogenase deficiencies. Unlike the latter, however, the prognosis regarding survival and response to treatment appears to be very bad according to the literature.

Of 25 patients reported with presumed or proven long-chain HAD-deficiency, 17 died during an acute attack either before therapy or despite therapy (Dionisi Vici et 
al., 1990; Hagenfeldt et al., 1990, Pollitt, 1990; Rocchiccioli et al., 1990). As a rule, the disease became manifest in the first months of life with symptoms resembling Reye syndrome. Repeated acute episodes are quite typical, often triggered by upper respiratory or gastrointestinal infections.

There were reports on 10 siblings of patients who had died earlier during similar crises with diagnosis of 'sudden infant death syndrome' or Reye syndrome (Hagenfeldt et al., 1990; Wanders et al., 1990; Pollitt, 1990). One of those siblings died on the third day of life (Wanders et al., 1990). In the two siblings who had died before their respective index cases the presumptive diagnosis of 3-hydroxydicarboxylic aciduria could be confirmed retrospectively by the demonstration of measurable concentrations of 3-hydroxy fatty acids of chain lengths between 6 and 10 carbon atoms and up to 18 carbon atoms in filter-paper blood samples obtained for neonatal screening and stored for up to 6 years (Von Döbeln et al., 1990).

Progressive or intermittent pathological change in liver with fatty infiltration and fibrosis or cirrhosis was found in at least 14 patients (Riudor et al., 1986; Poll-The et al., 1988; Hagenfeldt et al., 1990; Hale et al., 1990; Pollitt, 1990; Rocchiccioli et al., 1990). This was not the case in our patient.

As in other defects of fatty acid oxidation, most patients showed episodic hypoketotic hypoglycaemia with intolerance to fasting and secondary carnitine deficiency. Free and total carnitine was decreased in the plasma of a number of patients as well as in our patient and, in addition, was found to be low in a muscle and liver biopsy of one patient concomitantly with an increase of long-chain acylcarnitines (Hale et al., 1990). Primary (systemic) carnitine deficiency was the presumptive diagnosis in our patient before the identification of the 3-hydroxy fatty and dicarboxylic acids in urine. Muscular hypotonia and motor developmental retardation seemed to fit this diagnosis.

Unlike many patients in the literature, our patient's subsequent mental and motor development was normal. There were only three further mild attacks of metabolic dysregulation. This is most probably due to the very strict avoidance of hypoglycaemia and catabolism over all her years.

Signs of myopathy or cardiomyopathy (Ruidor et al., 1986; Dionisi Vici et al., 1990; Rocchiccioli et al., 1990) have not been found in this patient. Neither could peripheral neuropathy be demonstrated. This was a prominent finding in four other cases (Poll-The et al., 1988; Dionisi Vici et al., 1990).

Until recently our patient appeared to be similar to one patient reported by Pollitt (1990), who after one first attack of a Reye syndrome-like picture was normal. When she was treated with a carbohydrate-enriched diet in frequent meals with a nocturnal fasting period of less than $7 \mathrm{~h}$ plus extra L-carnitine, we were no longer able to find the abnormal 3-hydroxy acids in her urine.

The demonstration of a retinal pigment dystrophy, which has been found in four other patients (Riudor et al., 1986; Poll-The et al., 1988; Dionisi Vici et al., 1990), however, will necessitate careful follow-up of this patient. Especially in view of the favourable course of her disease and of the absence of chemical indices for metabolic derangement, it is a disturbing thought that this serious complication has arisen, perhaps as an obligatory long-term consequence of the metabolic defect. 


\section{REFERENCES}

Dionisi Vici, C., Bertini, E., Burlina, A., Garavaglia, B., Hale, D. E., Bertuli, A., Mazziotta, M. R. M., Sabetelli, M. and Sabetta, G. Neuromuscular involvement in two unrelated children with long-chain 3-hydroxyacyl-CoA dehydrogenase (LCHAD) deficiency. Pediatr. Res. 28 (1990) 305

Hagenfeldt, L., von Döbeln, U., Holme, E., Alm, J., Brandberg, G., Enocksson, E. and Lindeberg, L. 3-Hydroxydicarboxylic aciduria - a fatty acid oxidation defect with severe prognosis. J. Pediatr. 116 (1990) 387-392

Hale, D. E. and Thorpe, C. Short-chain 3-OH acyl-CoA dehydrogenase deficiency. Pediatr. Res. 25 (1989) 199A

Hale, D. E., Thorpe, C., Braat, K., Wright, J. H., Roe, C. R., Coates, P. M., Hashimoto, T. and Glasgow, A. M. The L-3-hydroxyacyl-CoA dehydrogenase deficiency. In Tanaka, K. and Coates, P. M. (eds.) Fatty Acid Oxidation, Alan R. Liss, New York, 1990, pp. 503-510

Jakobs, C., Bojasch, M., Mönch, E., Rating, D., Siemes, H. and Hanefeld, F. Urinary excretion of gamma-hydroxybutyric acid in a patient with neurological abnormalities. Clin. Chim. Acta 111 (1981) 169-178

Kelley, R. I. and Morton, D. H. 3-Hydroxyoctanoic aciduria: identification of a new organic acid in the urine of a patient with non-ketotic hypoglycemia. Clin. Chim. Acta 175 (1988) $19-26$

Pollitt, R. J. Clinical and biochemical presentation in 20 cases of hydroxydicarboxylic aciduria. In Tanaka, K. and Coates, P. M. (eds.) Fatty Acid Oxidation, Alan R. Liss, New York, 1990, pp. 495-502

Poll-The, B. T., Bonnefont, J. P., Ogier, H., Charpentier, C., Pelet, A., le Fur, J. M., Jakobs, C., Kok, R. M., Duran, M., Divry, P., Scotto, J. and Saudubray, J. M. Familial hypoketotic hypoglycemia associated with peripheral neuropathy, pigmentary retinopathy and $C_{6}-C_{14}$ hydroxydicarboxylic aciduria. A new defect in fatty acid oxidation? J. Inher. Metab. Dis. 11, Suppl. 2 (1988) 183-185

Ribes, A., Riudor, E., Sancho, S., Navarro, C., Figueras, C., Sune, J. and Roig, M. Tiglylglycine in two patients with $\mathrm{C}_{6}-\mathrm{C}_{14}$ 3-hydroxydicarboxylic aciduria: points to a long-chain ketoacylCoA thiolase deficiency. Abstracts: SSIEM Annual Meeting, Munich, 1989, Poster P104

Riudor, E., Ribes, A., Boronat, M., Sabado, C., Dominguez, C. and Ballabriga, A. A new case of $\mathrm{C}_{6}-\mathrm{C}_{14}$ dicarboxylic aciduria with favourable evolution. $J$. Inher. Metab. Dis. 9, Suppl. 2 (1986) 297-299

Rocchiccioli, F., Wanders, R. J. A.s Aubourg, P., Vianey-Liaud, C., Ijlst, L., Fabre, M., Cartier, N. and Bougnères, P. F. Deficiency of long-chain 3-hydroxyacyl-CoA dehydrogenase: a cause of lethal myopathy and cardiomyopathy in early childhood. Pediatr. Res. 28 (1990) $657-662$

Von Döbeln, U., Venizelos, N. and Hagenfeldt, L. Retrospective diagnosis of 3-hydroxydicarboxylic aciduria by analysis of filter paper blood samples. J. Inher. Metab. Dis. 13 (1990) $165-168$

Wanders, R. J. A., Purvis, Y. R., Heymans, H. S. A., Bakkeren, J. A. J. M., Parmentier, G. G., van Eldere, J., Eyssen, H., van den Bosch, H., Tager, J. M. and Schutgens, R. B. H. Age related differences in plasmalogen content of erythrocytes from patients with the cerebrohepato-renal (Zellweger) syndrome: implications for postnatal detection of the disease. $J$. Inher. Metab. Dis. 9 (1986a) 335-342

Wanders, R. J. A., van Roermund, C. W. T., de Vries, C. T., v. d. Bosch, H., Schrakamp, G., Tager, J. M., Schram, A. W. and Schutgens, R. B. H. Peroxisomal $\beta$-oxidation of palmitoyl$\mathrm{CoA}$ in human liver homogenates and its deficiency in the cerebro-hepato-renal (Zellweger) syndrome. Clin. Chim. Acta 159 (1986b) 1-10

Wanders, R. J. A., Duran, M., Ijlst, L., de Jager, J. P., van Gennip, A. H., Jakobs, C., Dorland, L. and van Sprang, F. J. Sudden infant death and long-chain 3-hydroxyacyl-CoA dehydrogenase. Lancet 2 (1989) 52-53 
Wanders, R. J. A., Ijlst, L., van Gennip, A. H., Jakobs, C., de Jager, J. P., Dorland, L., van Sprang, F. J., Duran, M. Long-chain 3-hydroxyacyl-CoA dehydrogenase deficiency: identification of a new inborn error of mitochondrial fatty acid $\beta$-oxidation. J. Inher. Metab. Dis. 13 (1990) $311-314$

J. Inher. Metab. Dis. 14 (1991) 680

(C) SSIEM and Kluwer Academic Publishers. Printed in the Netherlands

\section{BOOK REVIEW}

Techniques in Diagnostic Human Biochemical Genetics - a laboratory manual. Edited by F. A. Hommes. Wiley-Liss, New York, 1991. ISBN 0-471-56076-6, 660 pp., $\$ 69.50$.

Few books deal with the techniques required for the diagnosis of biochemical genetic disorders. Most methods are developed within specialist laboratories, often finely tuned to individual needs and not always well documented. This book was produced as a result of a programme of proficiency testing in North American laboratories that provide a diagnostic service in biochemical genetics. The book contains 33 chapters, written by well-established authorities, with special emphasis on the handling and interpretation of results. Opening chapters are on laboratory organization, statistics, data management and transmission of results, followed by a useful chapter on general metabolic screening. The next twenty chapters deal with analysis of nonprotein metabolites - such as sugars, glycosaminoglycans, amino acids, phenylalanine and tyrosine, organic acids (an excellent reference source on GS-MS), very-longchain fatty acids, phytanic acid, pipecolic acid, urinary oligosaccharides, sialic acid, tissue gangliosides and glycosphingolipids, galactose metabolites and associated enzymes, as well as a useful chapter on lactate/pyruvate and ketone bodies. Chapters follow on carnitine, porphyrins, orotate, oxalate, pterins, purines and pyrimidines. The last eight chapters address defects manifest in proteins such as those in lipoproteins, $\alpha_{1}$-antitrypsin and haemoglobins, as well as screening of maternal serum $\alpha$-fetoprotein. Finally there is a short chapter on biotinidase followed by one on radiometric assay of enzymes associated with mucopolysaccharidoses with the last chapter on other lysosomal enzymes often assayed for screening.

There is no doubt that this book will find a useful place on the laboratory bench rather than the library shelf. It contains a wealth of useful information, although different laboratories will regret the omission of subjects such as the glycogenoses, cell culture techniques and use of these cells in oxidation and other studies. This book nevertheless represents good value for money and is clearly to be recommended to all involved in the diagnosis of metabolic disease at the biochemical level.

G. T. N. Besley

Top Grade Biochemist 